\title{
Clinical Factors Associated with Weight Gain in French-Canadian Children and Adolescents Treated With Second Generation Antipsychotics: A 24-Month Retrospective Study
}

\author{
Drigissa Ilies ${ }^{1}$, Anne Sophie Huet ${ }^{1}$, Geneviève Roy ${ }^{2}$,Emmanuel Stip ${ }^{3}$ and Leila Ben Amor ${ }^{1 *}$ \\ ${ }^{1}$ Department of Psychiatry, University of Montreal, Canada \\ ${ }^{2}$ Department of Psychiatry, University of Quebec, Canada \\ ${ }^{3}$ Psychiatrist, University of Montreal Hospital's Research Center, Canada
}

Submission: August 21, 2017; Published: October 16, 2017

*Corresponding author: Leila Ben Amor, Child and adolescent psychiatrist, Associate Professor, Department of Psychiatry, CHU Sainte-Justine, University of Montreal, 3175 Chemin de la Côte Sainte Catherine, Montréal, Québec, H3T 1C5, 514/345 4931, 3397,

Email: leila.ben.amor.hsj@ssss.gouv.qc.ca

\begin{abstract}
Objective: To describe clinical factors associated with SGA-induced weight gain induced by long-term second generation antipsychotic (SGA) treatment in children and adolescents.

Methods: A 24-month retrospective study conducted between November 2005 and June 2013. 147 antipsychotic-naive patients were selected [mean age 12.8; (95\% CI 9.8 to 15.9)] and treated with an SGA (risperidone, olanzapine, quetiapine and aripiprazole) for up to 24 months. Weight and height were measured and BMI (body mass index) z-scores were calculated at baseline, 1, 3, 6, 12 and 24 months. Linear mixed-model analysis was used to compare weight, BMI and BMI z-score changes of the SGA treatment with the repeated factor being the time relative to baseline at $1,3,6,12$ and 24 months.

Results: After 24 months of SGA treatment, mean weight increased significantly by $12.8 \mathrm{~kg}$ (95\% CI 10.4 to 15.0 ) and BMI z-score by 0.44 ( $95 \%$ CI 0.21 to 0.68 ). Incidence of overweight/obesity was $22.6 \%$ and significant BMI z-score increase over 0.5 was $9.4 \%$. Older age ( $p=0.001$ ), male sex $(\mathrm{p}=0.002)$ and diagnosis of mood disorder $(\mathrm{p}=0.0004)$ were associated with a significant increase in weight gain. Lower baseline BMI $\mathrm{z}$-score $(\mathrm{p}<0.0001)$ and presence of mood disorder $(\mathrm{p}=0.011)$ had a significant impact on BMI $\mathrm{z}$-score augmentation.
\end{abstract}

Conclusion: Older age, male sex, lower baseline BMI z-score and diagnosis of mood disorder were associated to more pronounce SGAinduced weight gain.

Keywords: Second generation antipsychotics; Weight gain; Children; Adolescents

\section{Introduction}

Second generation antipsychotics (SGAs), which are medications used to treat a variety of psychiatric disorders, are associated with weightgain, obesity, and increased cardiovascular risk in children, adolescents as well as in adult populations [1-3]. A source of concern is increasing evidence suggesting a greater or exigenic effect of SGAs in youth compared to adults [3-8], especially considering childhood obesity adversely affects nearly every organ system, causing substantial morbidity and mortality in adulthood [9].

Multiple factors have been associated with SGA-induced cardio-metabolic side effects, such as SGA type, dose, treatment duration, previous exposure or SGA polypharmacy, subject's age, sex or illness-related factors, but there is little consensus over their respective effects $[2,3,5,6,10,11]$. Among SGAs, olanzapine and clozapine are associated with the most important weight gain risk, followed by quetiapine and risperidone, and finally by aripiprazole and ziprasidone which have the lowest risk $[3,12]$. The findings of some, but not all, studies suggest that women have a greater vulnerability to antipsychotic-induced weight gain that men $[2,3]$. Evidence in the antipsychotic-drugnaïve pediatric population suggest a dose-dependent effect of risperidone on weight gain and lipid profiles as well as dose dependent effect of olanzapine on serum lipids and blood 
glucose levels [13]. The impact of the treatment duration on the weight gain remains a subject of debate as some studies showed an attenuation of the weight gain over time with a plateau around 6 or 12 months [1,14-18], whereas others demonstrated a continuous weight increase over time [19-21]. Anyhow, data on the long term metabolic effects of antipsychotics in pediatric populations are scarce [3]. The heterogeneous results regarding moderating variables could be explained in part by the different methodologies and study samples found across studies.

The aim of this study is to describe clinical factors associated with the SGA-induced weight and increase in BMI z-score in antipsychotic-naive children and adolescents, in the "reallife" clinical setting. We hypothesize that older age, female sex, lower baseline BMI z-score and polypharmacy other than with psychostimulants will be associated with more important weight gain, in accordance with actual literature $[2,3,6,7]$.

\section{Subjects and Methods}

\section{Study design}

The medical charts of the inpatients and outpatients from the "Second-Generation Antipsychotic Monitoring Program" at Hotel-Dieu de Lévis Hospital (Quebec, Canada) between November 2005 and June 2013 were retrospectively reviewed. The population in the area deserved by the department of child psychiatry is almost exclusively of French-Canadian origin. All study procedures were reviewed and approved by the local ethics and research committee (CER-1213-018).

\section{Study subjects}

The inclusion criteria for the study subjects were being under 18 years old, having no previous history of antipsychotic treatment and having received treatment with an SGA for at least one month during the study. The exclusion criteria included preexisting dyslipidemia, diabetes or receiving medications for metabolic conditions. For each patient, we gathered information for age, sex, psychiatric diagnoses, SGA treatment (total dose/ day, duration of use), other medications (total dose/day, duration of use), height and weight. The height and weight were measured at baseline, 1, 3, 6, 12 and 24 months by a nurse. Diagnoses were made by a child psychiatrist in accordance with the Diagnostic and Statistical Manual of Mental Disorders, Fourth Edition, Text Revision (DSM IV-TR) criteria. Clinical data was collected from the chart notes. The main diagnosis was considered the one for which the SGA was prescribed. In many cases, more than one main diagnosis was recorded because SGAs were used to treat symptoms common to many diagnostics, such as disruptive behavior and ADHD. The other medications given in adjunct with the SGA were grouped in four categories: psychostimulants (amphetamine-based, methylphenidate-based), atomoxetine (to more accurately discriminate the potential metabolic impact with psychostimulants), antidepressants (bupropion, citalopram, fluvoxamine, sertraline, venlafaxine) and mood stabilizers (carbamazepine, lithium, valproic acid).

\section{Treatment}

The patients received SGAs (olanzapine, risperidone, quetiapine or aripiprazole) in monotherapy (the same SGA was prescribed from the beginning to the end of the period of the follow-up) or in polytherapy (switched from one SGA to another or used a combination of two SGAs, with the second SGA added between 0.5 and 24 months).

\section{Measures}

The variables studied were weight, BMI-calculated as weight $(\mathrm{kg}) /$ height squared $\left(\mathrm{m}^{2}\right)$-and standardized BMI z-scorecalculated using the children's BMI percentile-for-age calculator from the Children's Nutrition Research Center, Baylor College of medicine website (http://www.bcm.edu/cnrc--- apps/ bodycomp/bmiz2.html). The exact day of weight measurement was not always available in the charts; therefore, we calculated the BMI z-scores as if the patients were always weighed on the first day of the month to minimize the measurement bias. The BMI z-score represents the BMI adjusted for age and sex, thus considering the weight gain attributable to the growth process. It allows the comparison between the BMI of children and adolescents of the same age and sex [22]. Overweight was defined as BMI z-scores between the 85th and 95th percentile and obesity as BMI z-scores greater than or equal to the 95th percentile [23]. The doses of each SGA were converted in chlorpromazine equivalents [24].

\section{Statistical Analysis}

The statistical analysis included all the patients with data available at baseline and at least at one follow-up assessment time. The characteristics of the sample are presented as means (95\% CI) for the continuous variables and as frequencies or percentages for the categorical variables. We assessed changes secondary to SGA treatment in continuous outcomes using the linear mixed model with repeated measures. The repeated factor was the time relative to baseline at 1, 3, 6, 12 and 24 months. Since the measures were collected from retrospective chart review, they reflect 'real-life' clinical situations not always strictly respecting follow-up time intervals. We averaged data for plus or minus one month interval (for example, the third month corresponds to data from the second to the fourth months).

Incidence was calculated as the proportion of new-onset metabolic complications at each time point divided by the number of patients with available data. For each outcome, we adjusted for age and sex plus other medications associated with SGA or primary psychiatric diagnosis, thus yielding two different analyses. Summary statistics are presented as adjusted means of change over time $(95 \% \mathrm{CI})$. All analyses were made using SAS 9.3 (SAS Institute Inc., North Carolina, USA). The threshold for statistical significance was set at $\mathrm{p}<0.05$.

\section{Results}

Figure 1 A total of 147 patients treated for the first time with an SGA between November 2005 and June 2013 were 


\section{Current Research in Diabetes \& Obesity Journal}

included in the study. One hundred sixteen $(78.9 \%)$ of them received an SGA in monotherapy and 31 (21.1\%) received an SGA polytherapy (20 subjects switched SGAs and 11 received a combination of two SGAs). Subjects were almost exclusively French Canadian. The category 'Other' primary psychiatric diagnosis included personality disorder, mental retardation, pervasive developmental disorder and obsessive-compulsive disorder.



Table 1: Clinical characteristics of children and adolescents treated with SGAs.

\begin{tabular}{|c|c|}
\hline \multicolumn{2}{|c|}{ Demographics } \\
\hline Age, years, mean $(95 \% \mathrm{CI})$ & $12.8(9.8-15.9)$ \\
\hline Sex, male, n(\%) & $107(72.8)$ \\
\hline \multicolumn{2}{|c|}{ Primary Psychiatric Diagnosis, n (\%) } \\
\hline Psychotic disorder & $45(30.6)$ \\
\hline Mood disorder & $34(23.1)$ \\
\hline Tic disorder & $14(9.5)$ \\
\hline $\begin{array}{c}\text { Disruptive behavioral disorder } \\
\text { with ADHD }\end{array}$ & $90(61.2)$ \\
\hline Other & $17(11.6)$ \\
\hline
\end{tabular}

Baseline Anthropometric Measures, Mean (95\% CI)

\begin{tabular}{|c|c|}
\hline Weight $(\mathrm{kg})$ & $47.6(32.4-61.2)$ \\
\hline BMI & $20.1(16.8-22.5)$ \\
\hline BMI z-score & $0.2(-0.6-0.9)$ \\
\hline Baseline Weight Status, $\mathrm{n}(\%)$ & $8(6.1)$ \\
\hline Underweight $\left(<5^{\text {th }}\right.$ percentile $)$ & $96(73.3)$ \\
\hline Normal & $16(12.2)$ \\
\hline $\begin{array}{c}\text { Overweight }\left(\geq 85^{\text {th }}<95^{\text {th }}\right. \\
\text { percentile })\end{array}$ & $11(8.4)$ \\
\hline Obese $\left(\geq 95^{\text {th }}\right.$ percentile $)$ & \\
\hline
\end{tabular}

SGA Dose Chlorpromazine Equivalent, [mg/day, mean (95\% CI)]

\begin{tabular}{|c|c|}
\hline Olanzapine & $175.3(100.0-300.0)$ \\
\hline Risperidone & $52.3(25.3-67.1)$ \\
\hline Quetiapine & $171.3(44.4-266.7)$ \\
\hline Aripiprazole & $90.6(42.2-116.7)$ \\
\hline
\end{tabular}

Other Medications Associated with SGAs, n(\%)

\begin{tabular}{|c|c|}
\hline Psychostimulant & $75(51.0)$ \\
\hline Antidepressant & $46(31.3)$ \\
\hline Mood stabilizer & $35(23.8)$ \\
\hline Atomoxetine & $29(19.7)$ \\
\hline
\end{tabular}

Table 2: Impact of clinical characteristics on weight, BMI and BMI Z-score changes.

\begin{tabular}{|c|c|c|c|c|c|c|c|c|c|c|}
\hline $\begin{array}{c}\text { Clinical } \\
\text { Characteristic }\end{array}$ & \multicolumn{2}{|l|}{ Age } & \multicolumn{2}{|l|}{ Sex } & \multicolumn{2}{|c|}{ Baseline Value } & \multicolumn{2}{|c|}{ Main Diagnosis } & \multicolumn{2}{|c|}{$\begin{array}{c}\text { Other Medications } \\
\text { Associated With SGA }\end{array}$} \\
\hline \multirow{2}{*}{$\begin{array}{l}\text { Outcome } \\
\text { Variable }\end{array}$} & \multirow[b]{2}{*}{$\begin{array}{c}\text { Mean (95\% } \\
\text { CI) }\end{array}$} & \multirow[b]{2}{*}{$\mathbf{p}$} & \multicolumn{2}{|l|}{ Male } & \multirow[b]{2}{*}{$\begin{array}{c}\text { Mean (95\% } \\
\text { CI) }\end{array}$} & \multirow[b]{2}{*}{$\mathbf{p}$} & \multicolumn{2}{|c|}{ Mood Disorder } & \multicolumn{2}{|c|}{ Mood Stabilizers } \\
\hline & & & $\begin{array}{c}\text { Mean (95\% } \\
\text { CI) }\end{array}$ & p & & & $\begin{array}{l}\text { Mean (95\% } \\
\text { CI) }\end{array}$ & $\mathbf{p}$ & $\begin{array}{l}\text { Mean (95\% } \\
\text { CI) }\end{array}$ & $\mathbf{p}$ \\
\hline Weight (kg) & $\begin{array}{c}0.38 \\
(0.15 \text { to } 0.61)\end{array}$ & 0.001 & $\begin{array}{c}1.89 \\
(0.73 \text { to } 3.06)\end{array}$ & 0.002 & $\begin{array}{c}-0.03 \\
(-0.07 \text { to } 0.006)\end{array}$ & 0.099 & $\begin{array}{c}2.49 \\
\text { (1.15 to } 3.83)\end{array}$ & 0.0004 & $\begin{array}{c}0.89 \\
(-0.42 \text { to } 2.21)\end{array}$ & 0.182 \\
\hline BMI z---score & & & & & $\begin{array}{c}-0.21 \\
(-0.29 \text { to }-0.13)\end{array}$ & $<0.0001$ & $\begin{array}{c}0.28 \\
(0.07 \text { to } 0.49)\end{array}$ & 0.011 & $\begin{array}{c}0.19 \\
(-0.01 \text { to } 0.38)\end{array}$ & 0.0651 \\
\hline BMI (kg/m2) & $\begin{array}{c}0.09 \\
(0.02 \text { to } \\
0.17)\end{array}$ & 0.016 & $\begin{array}{c}-0.40 \\
(-0.89 \text { to } \\
-0.09)\end{array}$ & 0.114 & $\begin{array}{c}-0.07 \\
(-0.12 \text { to } \\
-0.01)\end{array}$ & 0.02 & $\begin{array}{c}0.99 \\
(0.43 \text { to } \\
1.56)\end{array}$ & 0.0007 & $\begin{array}{c}0.47 \\
(-0.07 \text { to } \\
1.01)\end{array}$ & 0.087 \\
\hline
\end{tabular}




\section{Current Research in Diabetes \& Obesity Journal}

Further data presented originates from the analysis controlling for age, sex and co-medications Table 1. The other analysis (controlling for age, sex and primary diagnosis) yielded similar results. After 24 months of SGA treatment, mean weight increased significantly by $12.8 \mathrm{~kg}(95 \%$ CI $10.4-15.0, \mathrm{p}<0.0001)$ and BMI z-score increased by 0.44 (95\% CI 0.21-0.68, $\mathrm{p}=0.0002$ ).

Incidence of newly developed conditions is considerable as $22.6 \%$ of subjects became overweight or obese and $42.9 \%$ had a significant BMI z-score increase over 0.5 after two years of treatment. Table 2 Compared to younger age, older age was associated with a superior mean gain weight of $0.38 \mathrm{~kg}$ $(\mathrm{p}=0.001)$. Males gained a mean of $1.89 \mathrm{~kg}$ more than females $(\mathrm{p}=0.002)$ and subjects with a mood disorder, a mean $2.49 \mathrm{~kg}$ extra compared to the absence of mood disorder $(p=0.0004)$. A lower baseline BMI $\mathrm{z}$-score $(\mathrm{p}<0.0001)$ and the presence of mood disorder $(\mathrm{p}=0.011)$ had a significant impact on BMI z-score augmentation.

\section{iscussion}

In this retrospective study, older patients, males, those with a lower baseline BMI z-score and subjects with a primary diagnosis of mood disorder had a significantly more pronounced weight gain and BMI z-score increase after up to 24 months of SGA therapy. Clinical characteristics as older age and lower baseline BMI z-score have already been associated with an increased SGA-induced weight gain in children and adolescents $[10,25]$. In adults, even if low baseline BMI has frequently been associated with greater antipsychotic-induced weight gain, controversy still exist over this potential influence as this might be due-at least partially-to a regression to the mean effect and not to an underlying biological factor $[2,26]$.

Counter to our hypothesis, female sex [10] and concomitant use of mood stabilizers [7] were not associated with a more important weight gain. An unexpected finding was male sex being significantly associated with more weight gain that female sex. In agreement with our study (in which most subjects were treated with risperidone), Saklad et al. [27] found that male sex was associated with a more pronounced weight gain in youth treated with risperidone [27]. Another study analyzing metabolic changes in youth treated with risperidone showed no association between sex, age or baseline BMI and the SGAinduced weight gain [28], although this might be due to their small sample size ( 37 subjects compared to 147 in our study). Our subjects treated for mood disorder with SGAs had a significantly more pronounced weight gain and BMI z-score increase. We found only one short-term study comparing SGA-induced weight gain between bipolar, psychotic and non-psychotic disorders in children and adolescents, which failed to demonstrate an association between mood disorders and weight gain [29]. In our study, the association of mood disorders with a more important weight gain could be explained -at least partiallyby the metabolic risk conferred by a more severe pathology, as individuals with psychosis and bipolar disorder appear to have higher baseline metabolic risk than the general population [30].
Although mood stabilizers such as lithium and valproate have been associated with mild weight gain [7,31], we did not find an association between the concomitant use of mood stabilizers with SGAs and more important weight or BMI z-score increase. Only a tendency was found, possibly due to our study's relatively small sample size.

\section{Limitations}

The results of this study should be interpreted in consideration of its limitations. Due to the naturalistic design, the metabolic monitoring at 12 and 24 months was relatively low, which limited data available for the analyses and influenced the statistical power of our results. Also, all four SGAs (risperidone, olanzapine, quetiapine, aripiprazole) were regrouped thus preventing us from evaluating their respective effects-however not enough subjects were available to analyze each molecule separately. Additionally, 'a confounding by indication' bias should be considered when interpreting the results, as physicians might have prescribed a specific SGA depending on the baseline weight of the patient [6]. Moreover, given the variability of SGA doses in the clinical sample, we were unable to adjust the statistical analyses for the SGA chlorpromazine-equivalent dose. Finally, the homogeneity of the population sample analyzed in our study can limit the generalizability of the results.

\section{Strengths}

Aside from being a limitation, the genetic homogeneity of our sample confers an asset, as with the subjects being almost exclusively French Canadian the differences attributable to ethnic genetic diversity are limited. Also, our recruitment was restricted to an antipsychotic-naïve population, leading to more accurate conclusions about the first exposure to SGAs. Finally, this is one of the few long-term studies of metabolic complications in children and adolescents informing on weight gain and clinical factors associated with SGA use in drug-naïve populations.

\section{Conclusion}

In summary, we described that older age, lower baseline BMI z-score, male sex and primary diagnosis of mood disorder were associated with more pronounced SGA-induced weight gain, on one hand consolidating previous findings, and on the other eliciting more possible factors implicated in the vulnerability to SGA-induced weight gain: male sex and mood disorder. This information is valuable as it provides insight for physicians about clinical characteristics of patients having increased vulnerability of weight gain when treated with an SGA.

Clinicians should carefully monitor metabolic side effects as they were related not only to physical health complications but also to mental health problems, psychosocial dysfunction and poor treatment adherence [2,32]. Long-term prospective studies with larger sample sizes and control groups are needed to investigate the predictive factors of metabolic complications induced by SGAs. 


\section{Current Research in Diabetes \& Obesity Journal}

\section{Acknowledgement}

We would like to acknowledge the contribution of Isabelle Sanchez, research assistant, for assistance with the organization of the data.

\section{References}

1. Roy G, Bedard A, Desmarais PA, Jourdain F, Allen S, et al. (2010) Age dependent metabolic effects of second generation antipsychotics in second generation antipsychotic naive French Canadian patients. J Child Adolesc Psychopharmacol 20(6): 479-487.

2. Correll CU, Lencz T, Malhotra AK (2011) Antipsychotic drugs and obesity. Trends Mol Med 17(2): 97-107.

3. De Hert M, Detraux J, van Winkel R, Yu W, Correll CU (2012) Metabolic and cardiovascular adverse effects associated with antipsychotic drugs. Nature Rev Endocrinol 8(2): 114-126.

4. Correll CU, Sheridan EM, DelBello MP (2010) Antipsychotic and mood stabilizer efficacy and tolerability in pediatric and adult patients with bipolar I mania: a comparative analysis of acute, randomized, placebocontrolled trials. Bipolar Disorders 12(2): 116-141.

5. Maayan L, Correll CU (2011) Weight gain and metabolic risks associated with antipsychotic medications in children and adolescents. J Child Adolesc Psychopharmacol 21(6): 517-535.

6. Martinez Ortega JM, Funes Godoy S, Diaz Atienza F, Gutierrez Rojas L, Perez Costillas L, et al. (2013) Weight gain and increase of body mass index among children and adolescents treated with antipsychotics: a critical review. Eur Child Adolesc Psychiatry 22(8): 457-479.

7. Correll CU, Detraux J, De Lepeleire J, DeHert M (2015) Effects of antipsychotics, antidepressants and mood stabilizers on risk for physical diseases in people with schizophrenia, depression and bipolar disorder. World Psychiatry 14(2): 119-136.

8. Stafford M, Mayo Wilson E, Loucas CE, James A, Hollis C, et al. (2015) Efficacy and safety of pharmacological and psychological interventions for the treatment of psychosis and schizophrenia in children adolescents and young adults: a systematic review and meta-analysis PLos One 10(2): e0117166.

9. Han JC, Lawlor DA, Kimm SY (2010) Childhood obesity. Lancet 375(9727): 1737-1748.

10. McIntyre RS, Jerrell JM (2008) Metabolic and cardiovascular adverse events associated with antipsychotic treatment in children and adolescents. Arch Pediatr Adolesc Med 162(10): 929-935.

11. Rubin DM, Kreider AR, Matone M, Huang YS, Feudtner C, et al. (2015) Risk for incident diabetes mellitus following initiation of secondgeneration antipsychotics among medicaid-enrolled youths. JAMA Pediatr 169(4): e150285.

12. DeHert M, Dobbelaere M, Sheridan E, Cohen D, Correll CU (2011) Metabolic and endocrine adverse effects of second-generation antipsychotics in children and adolescents: A systematic review of randomized, placebo controlled trials and guidelines for clinical practice. Eur Psychiatry 26(3): 144-158.

13. Correll CU, Manu P, Olshanskiy V, Napolitano B, Kane JM, et al. (2009) Cardiometabolic risk of second-generation antipsychotic medications during first-time use in children and adolescents. JAMA 302(16): $1765-1773$

14. Croonenberghs J, Fegert JM, Findling RL, De Smedt G, Van Dongen S (2005) Risperidone in children with disruptive behavior disorders and subaverage intelligence: A 1-year, open-label study of 504 patients. J Am Acad Child Adolesc Psychiatry 44(1): 64-72.

15. Reyes M, Croonenberghs J, Augustyns I, Eerdekens M (2006) Longterm use of risperidone in children with disruptive behavior disorders and subaverage intelligence: Efficacy, safety, and tolerability. J Child Adolesc Psychopharmacol 16(3): 260-272.

16. Reyes M, Olah R, Csaba K, Augustyns I, Eerdekens M (2006) Longterm safety and efficacy of risperidone in children with disruptive behaviour disorders. Results of a 2-year extension study. Eur Child Adolesc Psychiatry 15(2): 97-104.

17. Fleischhaker C, Heiser P, Hennighausen K, Herpertz Dahlmann B, Holtkamp K, et al. (2008) Weight gain in children and adolescents during 45-week treatment with clozapine, olanzapine and risperidone. J Neural Transm 115(11): 1599-1608.

18. Calarge CA, Xie D, Fiedorowicz JG, Burns TL, Haynes WG (2012) Rate of weight gain and cardiometabolic abnormalities in children and adolescents. J Pediatr 161(6): 1010-1015.

19. Ronsley R, Nguyen D, Davidson J, Panagiotopoulos C (2015) Increased risk of obesity and metabolic dysregulation following 12 months of second-generation antipsychotic treatment in children: a prospective cohort study. Can J Psychiatry 60(10): 441-450.

20. Haddad PM, Sharma SG (2007) Adverse effects of atypical antipsychotics: differential risk and clinical implications. CNS Drugs 21(11): 911-936.

21. Henderson DC, Cagliero E, Gray C, Nasrallah RA, Hayden DL, et al. (2000) Clozapine, diabetes mellitus, weight gain, and lipid abnormalities: A five-year naturalistic study. Am J Psychiatry 157(6): 975-981.

22. Correll CU, Carlson C (2006) Endocrine and metabolic adverse effects of psychotropic medications in children and adolescents. J Am Acad Child Adolesc Psychiatry 45(7): 771-791.

23. Ogden CL, Kuczmarski RJ, Flegal KM, Mei Z, Guo S, et al. (2002) Centers for disease control and prevention 2000 growth charts for the united states: improvements to the 1977 national center for health statistics version. Pediatrics 109(1): 45-60.

24. Woods SW (2003) Chlorpromazine equivalent doses for the newer atypical antipsychotics. J Clin Psychiatry 64(6): 663-667.

25. Calarge CA, Acion L, Kuperman S, Tansey M, Schlechte JA (2009) Weight gain and metabolic abnormalities during extended risperidone treatment in children and adolescents. J Child Adolesc Psychopharmacol 19(2): 101-109.

26. Allison DB, Loebel AD, Lombardo I, Romano SJ, Siu CO (2009) Understanding the relationship between baseline BMI and subsequent weight change in antipsychotic trials: effect modification or regression to the mean? Psychiatry Res 170(2-3): 172-176.

27. Saklad SR, Ketchi CM, Amrung SA (2002) Gender differences in weight gain among adolescents started on atypical antipsychotics. J Child Adolesc Psychopharmacol 12: 288-289.

28. Martin A, Landau J, Leebens P, Ulizio K, Cicchetti D, et al. (2000) Risperidone-associated weight gain in children and adolescents: a retrospective chart review. J Child Adolesc Psychopharmacol 10(4): 259-268.

29. Moreno C, Merchaaln Naranjo J, A Allvarez M, Baeza I, Alda JA, et al. (2010) Metabolic effects of second-generation antipsychotics in bipolar youth: comparison with other psychotic and nonpsychotic diagnoses. Bipolar Disorders 12(2): 172-184.

30. Fraguas D, Correll CU, Merchan Naranjo J, Rapado Castro M, Parellada M, et al. (2011) Efficacy and safety of second-generation antipsychotics in children and adolescents with psychotic and bipolar spectrum disorders: comprehensive review of prospective head-to-head and placebo-controlled comparisons. Eur Neuropsychopharmacol 21(8): 621-645.

31. McKnight RF, Adida M, Budge K, Stockton S, Goodwin GM, et al. (2012) Lithium toxicity profile: a systematic review and meta-analysis. Lancet 379(9817): 721-728. 
32. Maayan L, Correll CU (2010) Management of antipsychotic-related weight gain. Expert Rev Neurother 10(7): 1175-1200.

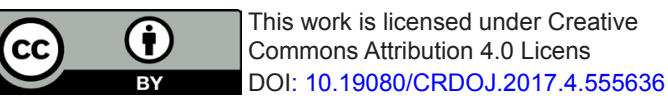

Your next submission with Juniper Publishers will reach you the below assets

- Quality Editorial service

- Swift Peer Review

- Reprints availability

- E-prints Service

- Manuscript Podcast for convenient understanding

- Global attainment for your research

- Manuscript accessibility in different formats

( Pdf, E-pub, Full Text, Audio)

- Unceasing customer service

Track the below URL for one-step submission https://juniperpublishers.com/online-submission.php 